anxiety. In addition, their cardiovascular disease risk factors scores were in the low and intermediate risk range.

\title{
71 THE RELATIONSHIP BETWEEN CARDIOVASCULAR RISK FACTORS AND TRAIT ANXIETY OF IRANIAN REFEREES AND ASSISTANT REFEREES IN PREMIER LEAGUE SOCCER
}

Effat Bambaeichi, Ahmad Reza Movahedi, Misam Abedini Faculty of Physical Education and Sport Sciences, University of Isfahan, Isfahan, Iran

10.1136/bjsm.2010.078725.71

The aim of this investigation was to explore the relationship between trait anxiety and cardiovascular disease risk factors of Iranian soccer referees and assistant referees. Twenty-five referees and 43 assistant referees (mean $\pm \mathrm{SD}$, age: $36.7 \pm 3.8$ years, height: $1.79 \pm 4.8 \mathrm{~m}$, weight: $74.7 \pm 6 \mathrm{~kg})$ with international $(22 \%$ of all subjects) and national (78\% of all subjects) degrees participated in this study. All referees were judging Premier League Soccer Competitions (2007-2008 season) under the supervision of Soccer Federation Referees committee. Trait anxiety was assessed by Zung Self-Rating Anxiety Scale and data regarding cardiovascular disease risk factors were obtained by cardiovascular disease risk factors (RISKO) questionnaire structured by Cardiovascular University of Michigan State in the USA. Blood pressure, heart rate and concentration of the cholesterol in blood serum were also measured. No significant difference was observed in trait anxiety score between soccer referees (34.4 \pm 4.9$)$ and assistant referees (32.2 \pm 4.7$)(p>0.05)$. There was no significant difference in RISKO score between soccer referees $(16.8 \pm 2.5)$ and assistant referees (16.8 \pm 2.5$)$. A significant relationship was not observed between trait anxiety and RISKO score in both referees $(r=0.26, p>0.05)$ and assistant referees $(r=0.11)$. Trait anxiety did not show significant relationship with age $(r=0.07)$, physical activity $(r=0.0)$, cholesterol $(r=-0.00)$ and blood pressure $(r=0.11)(p>0.05)$. A significant relationship was found between trait anxiety with weight $(\mathrm{r}=0.20, \mathrm{p}<0.05)$ and heredity of cardiovascular disease $(r=0.20, p<0.05)$. It can be concluded that Iranian referees and assistant referees in Premier League Soccer had normal trait 